COMUNICAÇÃO CIENTÍFICA

\title{
QUANTIFICAÇÃO DE AÇÚCARES EM PÊSSEGOS DA VARIEDADE BIUTI, ARMAZENADOS SOB CONDIÇÕES DE AMBIENTE E REFRIGERAÇÃO ${ }^{1}$
}

\author{
MARCELO ALVARES DE OLIVEIRA², MANRNEY PASCOLI CEREDA ${ }^{3}$, \\ CLÁUDIO CABELLO ${ }^{4}$, LUIZ HENRIQUE URBANO 5
}

\begin{abstract}
RESUMO - O objetivo deste trabalho foi identificar e quantificar os açúcares em frutos de pessegueiro da variedade 'Biuti', armazenados sob condições de ambiente $\left(27,3^{\circ} \mathrm{C} ; 70 \%\right.$ UR) e sob refrigeração $\left(4^{\circ} \mathrm{C} ; 90 \%\right)$, comparar as diferenças entre os teores de açúcares nas duas condições de armazenamento. A identificação e a quantificação precisa dos açúcares (glicose, frutose e sacarose) foi realizada por cromatografia em fase líquida HPLC. Verificou-se que a sacarose foi o açúcar encontrado em maior quantidade, sendo verificado apenas traços de glicose e frutose em alguns frutos. Sob condições ambientais, os teores de sacarose do $3^{0}$ até o $9^{0}$ dia de armazenamento não diferiram significativamente entre si; entretanto, no $12^{\circ}$ dia, os frutos obtiveram baixos teores de sacarose, pois os mesmos já estavam em processo de senescência. Sob refrigeração, o aumento nos teores de açúcares dos frutos ocorreu gradativamente durante todo o armazenamento, e ao final do mesmo, verificaram-se os maiores teores de sacarose, frutose e glicose, os quais eram mais elevados do que os encontrados nos frutos armazenados sob condições ambientais.
\end{abstract}

Termos de indexação: armazenamento, HPLC, sacarose, frutose e glicose

\section{QUANTIFICATION OF SUGARS IN 'BIUTI' VARIETY PEACHES STORAGE AT ENVIRONMENT CONDITIONS AND REFRIGERATION}

SUMMARY - This work had the objective to identify and to quantify the sugars of the 'Biuti' peaches stored under environment conditions $\left(27,3^{\circ} \mathrm{C} ; 70 \% \mathrm{UR}\right)$ and refrigeration $\left(4^{\circ} \mathrm{C} ; 90 \%\right)$. The method utilized was chromatography in liquid phase. In both experiments that the sucrose was the sugar found in the largest amount, being just verified traces of glucose and frutose in some fruits. The experiment in environmental conditions the values of sucrose of the $3^{\mathrm{RD}}$ to the $9^{\text {th }}$ day of storage didn't differ significantly, meantime in the $12^{\text {th }}$ day, the fruits obtained low sucrose values, because the fruits were already in the senescence process. Now, in the experiment under refrigeration the increase in the values of sugars of the fruits happened during the whole storage. The values of sucrose, frutose and glucose values were higher than the values found in the experiment in environmental conditions.

Index Terms: HPLC, sucrose, glucose, frutose,

O pessegueiro (Prunus persica L. Bastsch) é uma planta da família das rosáceas, originaria da Ásia. Dos frutos de clima temperado, é um dos mais perecíveis, em razão do seu rápido metabolismo após a colheita.

O Estado do Rio Grande do Sul é o maior produtor nacional de pêssego, colhendo cerca de dois terços da safra brasileira, sendo que $80 \%$ a $90 \%$ são destinados à fabricação de conserva. A colheita, no Brasil, dá-se entre agosto e março, época de entressafra nos grandes mercados consumidores do Hemisfério Norte, criando boas possibilidades de exportação.

O Estado de São Paulo produziu, no ano de 1996, 15.760 toneladas; no mesmo ano, o Rio Grande do Sul produziu cerca de 44.000 toneladas. O Brasil, neste ano, produziu cerca de 80.000 toneladas. Portanto, o Estado de São Paulo foi responsável por cerca de $20 \%$ da produção nacional (Agrianual, 2000).
A variedade 'Biuti' é bastante plantada no Estado de São Paulo, sendo a preferida à variedade 'Flor da Prince'. Entretanto, a 'Biuti' é uma variedade tardia que tem a sua safra iniciada em dezembro, quando o mercado está aquecido devido às festas de final de ano.

Os frutos climatéricos, como o pêssego, podem apresentar consideráveis mudanças no conteúdo de açúcares totais, que aumentam não só durante o período de sua maturação na árvore, como também durante o período entre a colheita e o ponto de amadurecimento para ser comestível. Há predominância de sacarose sobre os açúcares redutores (glicose + frutose), com aumento mais rápido na concentração deste açúcar, nas últimas semanas de maturação (Chitarra e Carvalho, 1985).

Desphande e Salunkhe (1964) também afirmaram que a sacarose é o açúcar encontrado em maior quantidade em

1 Trabalho $n^{\circ}$ 138/2000. Recebido: 12/07/2000. Aceito para publicação: 06/07/2001.

2 Eng. Agrônomo Doutor e Pesquisador do CERAT (Centro de Raízes Tropicais), Fazenda Experimental Lageado - 18603 -970 - CP 237 - Botucatu/ SP.e-mail:maoliveira@laser.com.br

3 Professora Titular da FCA-UNESP-Botucatu e Pesquisadora do CERAT (Centro de Raízes Tropicais), Fazenda Experimental Lageado - $18603-$ 970 - CP 237 -Botucatu/SP.

4 Professor Doutor da Faculdade de Ciências / UNESP -Bauru e Diretor do CERAT (Centro de Raízes Tropicais), Fazenda Experimental Lageado 18603-970 - CP 237 -Botucatu/SP.

5 CERAT (Centro de Raízes Tropicais), Fazenda Experimental Lageado - 18603-970 - CP 237 -Botucatu/SP. 
pêssegos, excedendo a de açúcares redutores.

Esti et al. (1997) trabalharam em cromatografia líquida (HPLC) com 12 cultivares de pêssegos da Itália: 'Babygold 9', 'Grezzano', 'Iris Rosso', 'Beauty Lady', 'Douceur', 'Felicia', 'Kurakata Wase', 'Lucie', 'Oro A', 'Royal Glory', 'Sensation' e 'Yumyeong' e verificaram que, para todas as cultivares, os teores de sacarose foram mais elevados do que os teores de frutose e glicose. Os teores de sacarose dos frutos variaram de 4,3\% a $9,8 \%$; os de glicose de $0,4 \%$ a $2,0 \%$ e os de frutose de $0,4 \%$ a $3,4 \%$.

Holland (1993) armazenou pêssegos da variedade 'Biuti' a $0^{\circ} \mathrm{C}+2^{\circ} \mathrm{C}$ e $95 \%$ UR, e concluiu que a variação nos teores de sacarose foi de $3,58 \%$ a $4,90 \%$ e de açúcares redutores (frutose + glicose) de $1,88 \%$ a $3,05 \%$.

Durante o amadurecimento, o fruto torna-se completamente maduro, pois os sabores e odores específicos desenvolvem-se e há aumento no teor de açúcares e diminuição no de acidez. Uma grande demanda de energia ocorre no sistema para a continuação dos processos metabólicos, com a hidrólise de carboidratos de cadeia longa e conseqüente aumento nos teores de sacarose, frutose e glicose. O objetivo deste trabalho foi identificar e quantificar os açúcares de frutos de pessegueiro da variedade 'Biuti', armazenada sob condições de ambiente e refrigeração.

Os frutos procederam do Sítio do Sr. Alberto Ueno localizado a $22^{\circ} 52^{\prime} 20^{\prime \prime}$ e latitude Sul e $48^{\circ} 26^{\prime} 37^{\prime \prime}$ de longitude Oeste, com 800 metros de altitude, no município de Botucatu-SP. Foram colhidos manualmente "de vez", em 12 de janeiro de 1999, e transportados no mesmo dia, em caixas de papelão, para o Departamento de Horticultura da Faculdade de Ciências Agronômicas do Câmpus de Botucatu - UNESP, onde foram realizados os experimentos. A variedade de pêssego utilizada foi a 'Biuti', que é "de mesa" e tardia. Os frutos foram selecionados quanto à coloração e ponto de maturação, visando à obtenção de um lote homogêneo.

Todos os frutos foram inicialmente mergulhados em suspensão aquosa aquecida $\left(52^{\circ} \mathrm{C}\right)$ durante 2 minutos, contendo 0,3g. $1^{-1}$ (Benomyl), com intuito de se evitar o aparecimento de podridões pós-colheita. Os frutos foram colocados em caixas de pêssegos/papelão ondulado II, de dimensões internas $480 \mathrm{~mm} \mathrm{X}$ $300 \mathrm{~mm}$ X 100mm, para acompanhamento dos experimentos.

Os pêssegos foram divididos em dois lotes, para montagens dos dois experimentos, o primeiro armazenado sob refrigeração e o outro sob condições de ambiente. No armazenamento sob refrigeração, a temperatura média foi de $4+2^{\circ} \mathrm{C}$ e a umidade relativa média, de $90+5 \%$, durante os 35 dias do experimento. No armazenamento sob condições de ambiente, foram registradas temperaturas médias de $27,2+3,0{ }^{\circ} \mathrm{C}$ e umidade relativa média de $70+11 \%$, durante 12 dias. Os frutos sob refrigeração foram avaliados a cada 7 dias e os sob condições de ambiente a cada 3 dias.

A identificação e a quantificação dos açúcares (glicose, frutose e sacarose) foram realizadas por cromatografia em fase líquida, HPLC (High Performance Liquid Chromatography). A coluna utilizada foi a HPX 87P e a pré-coluna 125-0119, ambas da marca BIORAD (Biorad, sd; Scott, 1992). A vazão da fase móvel foi de $0,8 \mathrm{ml} \cdot \mathrm{min}^{-1}$ e a temperatura da coluna de $80^{\circ} \mathrm{C}$. Na fase móvel, utilizou-se água desmineralizada, deionizada e filtrada a 0,22 mm. O tempo de retenção foi de 15 minutos.

Em ambos os experimentos, cada amostra foi composta por 2 frutos triturados conjuntamente, dando origem ao extrato aquoso. Utilizaram-se 3 repetições por retirada, perfazendo 6 frutos. Assim sendo, para o experimento sob refrigeração, utilizaram-se 30 frutos, e para o experimento sob condições ambientais, 24 frutos. Os conteúdos dos açúcares totais foram determinados no extrato aquosos dos frutos. Uma alíquota de material fresco triturado (1 grama) foi diluída em $10 \mathrm{ml}$ de água e, em seguida, centrifugada por 15 minutos a 5000 rpm e injetada em cromatógrafo HPLC, utilizando-se filtro de 0,22 $\mu \mathrm{m}$. Os resultados foram expressos em porcentagem, em relação à massa fresca inicial da amostra.

Para os teores de açúcares com valores significativos, utilizou-se o delineamento estatístico inteiramente casualizado. As médias foram comparadas ao nível de $5 \%$ de probabilidade, pelo teste de Tukey.

Em condições de ambiente, através das análises efetuadas, verificou-se que a sacarose foi o açúcar encontrado em maior quantidade, excedendo a quantidade de açúcares redutores (Tabela 1). Estes dados encontram apoio em Desphande e Salunkhe (1964), Chitarra e Carvalho (1985) e Esti et al. (1997).

Chitarra e Carvalho (1985) relataram para pêssegos teores de sacarose de 4,9\% a 8,0\% e de açúcares redutores (glicose + frutose) de 2,0\% a 3,2\%. Já Esti et al. (1997) relataram teores de sacarose de $4,3 \%$ a $9,8 \%$; de glicose de $0,4 \%$ a $2,0 \%$ e os de frutose de $0,4 \%$ a $3,4 \%$. Neste experimento, os teores de açúcares redutores nos pêssegos 'Biuti' variaram de $0,0 \%$ a $0,3 \%$ e de sacarose de $1,0 \%$ a $4,6 \%$, teores estes menores que os dos autores citados.

TABELA 1 - Valores médios obtidos para os teores de sacarose, frutose, glicose (\%) em pêssegos "Biuti", a cada 3 dias, armazenados sob condições de ambiente $\left(27,2+3{ }^{\circ} \mathrm{C}\right.$ e $70+11 \%$ UR). Botucatu, 1999.

\begin{tabular}{lccccc}
\hline & \multicolumn{3}{c}{ Dias de Armazenamento } \\
Açúcares & $\mathbf{3}$ & $\mathbf{6}$ & $\mathbf{9}$ & $\mathbf{1 2}$ & M édia \\
Sacarose & $3,6 \mathrm{a}$ & $3,8 \mathrm{a}$ & $4,6 \mathrm{a}$ & $1,9 \mathrm{~b}$ & 3,5 \\
Frutose & 0,0 & 0,0 & 0,0 & 0,0 & 0,0 \\
Glicose & 0,1 & 0,0 & 0,3 & 0,0 & 0,1 \\
Total & 3,7 & 3,8 & 4,9 & 1,9 & 3,6 \\
\hline
\end{tabular}

médias seguidas de letras minúsculas nas linhas, e iguais, não diferem significativamente entre si ( $\mathrm{p}>0.05)$.

c.v. $=20.67 \%$ 
Apresentaram também apenas traços de glicose e frutose, verificando-se a presença destes açúcares em apenas algumas amostras e em valores muito pequenos.

Em relação ao tempo de armazenamento, no $12^{\circ}$ dia, os frutos obtiveram baixos teores de sacarose, pois os frutos já estavam no processo de senescência. Parte da sacarose foi hidrolisada para que os monossacarídeos (glicose e frutose) fossem metabolizados para gerar energia aos processos.

Em relação aos teores de açúcares, o ponto ideal de consumo para os pêssegos, neste experimento, foi do $3^{0}$ ao $9^{0}$ dia de armazenamento.

Para os frutos armazenados sob refrigeração, através do perfil de açúcar, verificou-se que a sacarose foi o açúcar encontrado em maior quantidade, como ocorreu no experimento sob condições de ambiente, reafirmando os dados de Desphande e Salunkhe (1964) e Chitarra e Carvalho (1985) e Esti et al. (1997). (Tabelas 2).

Neste experimento, os teores de açúcares redutores variaram de $0,0 \%$ a $1,7 \%$ e a de sacarose de $0,7 \%$ a $5,6 \%$. Portanto, em relação a Chitarra e Carvalho (1985) e Esti et al. (1997), os resultados de açúcares redutores do experimento refrigerado e do experimento sob condições de ambiente foram inferiores.

Holland (1993) armazenou pêssegos da variedade 'Biuti' a $0+2^{\circ} \mathrm{C}$ e $95 \%$ de umidade relativa, e afirmou que a variação nos teores de sacarose foi de 3,6\% a 4,9\% e de açúcares redutores (frutose + glicose e outros açúcares com extremidades livres se existentes) de $1,9 \%$ a $3,1 \%$. Estes valores são similares aos encontrados neste experimento sob refrigeração para a sacarose; entretanto, os valores do início do experimento são menores devido a o fruto ter sido colhido "de vez", com o objetivo de se estender a pós-colheita. Com relação aos açúcares redutores, os valores são inferiores aos encontrados pelos autores citados. Não pudemos comparar os valores de glicose e frutose com os teores do autor citado, pois o mesmo não aferiu os teores destes açúcares separadamente.

Verificou-se que os frutos da variedade 'Biuti' apresentaram apenas traços de glicose e frutose; entretanto, com o uso da refrigeração, obtiveram-se maiores teores de açúcares redutores do que sob condições de ambiente. Embora as condições climáticas de cultivo e desenvolvimentos dos frutos tenham sido iguais às do experimento sob condições de ambiente, as baixas temperaturas diminuíram a velocidade de consumo de açúcares para a manutenção do metabolismo (hidrólise de sacarose e consumo de monossacarídeos), tornando os teores de sacarose, glicose e frutose mais elevadas.
Em relação ao tempo de armazenamento, verificou-se que os valores de sacarose, frutose e glicose aumentaram durante o armazenamento. Assim sendo, a diminuição nos teores de sacarose ocorrida no experimento sob condições de ambiente (hidrólise de sacarose e consumo de glicose e frutose), no final do armazenamento, não ocorreu no experimento refrigerado. Portanto, a refrigeração retardou o processo de senescência, não levando à diminuição nos teores de sacarose ao final do armazenamento.

Após 35 dias de armazenamento, em relação aos teores de açúcares, os frutos estavam em condição de consumo, com altos teores; entretanto, a característica visual já não era adequada, com escurecimento na pele e na polpa do mesmo, causada pela intensa ação da refrigeração.

Assim sendo, conclui-se que os açúcares encontrados nos frutos de pessegueiro variedade 'Biuti', armazenados sob condições ambientais ou sob refrigeração, foram à sacarose, a glicose e a frutose.

A sacarose foi o açúcar encontrado em maior quantidade, sendo verificado apenas traços de glicose e frutose em alguns frutos em ambos os experimentos.

No experimento sob condições ambientais, os teores de sacarose, glicose e frutose dos frutos de pessegueiro foram menores, devido à velocidade das reações serem maiores nesta condição, havendo um menor acúmulo dos mesmos.

\section{REFERÊNCIAS BIBLIOGRÁFICAS}

AGRIANUAL: Anuário da Agricultura Brasileira. São Paulo: FNP Consultoria \& Comércio, 2000., p. 454-9.

BIORAD. Manuais técnicos para pré-coluna e coluna HPLC. Califórnia, s.d.

CHITARRA, M.I.F.; CARVALHO, V.D. Qualidade e industrialização de frutos temperados: pêssegos, ameixas e figos. Informe Agropecuário, v.11, n.125, p.56-66, 1985.

DESPHANDE, P.B.; SALUNKE, D.K. Effecty of maturity and storage on certain biochemical changes in apricot and peaches. Food Technology, Chicago, v.18, p.1195-242, 1964.

ESTI, M. et al. Quality evaluation of peaches and nectarines by eletrochemical and multivariate analyses: relationships between

TABELA 2 - Valores médios obtidos para os teores de sacarose, frutose e glicose (\%) em pêssegos "Biuti", a cada 7 dias, e armazenados sob refrigeração $\left(4+2^{\circ} \mathrm{C}\right.$ e $90+5 \%$ UR). Botucatu, 1999.

\begin{tabular}{|c|c|c|c|c|c|c|}
\hline \multirow[b]{2}{*}{$A c ̧ u ́ c$ a res } & \multicolumn{6}{|c|}{ Dias de Armazenamento } \\
\hline & 7 & 14 & 21 & 28 & 35 & M é dia \\
\hline S a c a rose & $1,1 \mathrm{c}$ & $3,0 \mathrm{~b}$ & $2,4 \mathrm{bc}$ & $2,9 \mathrm{bc}$ & 5,6 a & 3,0 \\
\hline Frutose & 0,1 & 0,0 & 0,0 & 0,4 & 0,9 & 0,3 \\
\hline G licose & 0,1 & 0,0 & 0,0 & 0,3 & 0,8 & 0,2 \\
\hline Tota I & 1,3 & 3,0 & 2,4 & 3,6 & 7,3 & 3,5 \\
\hline
\end{tabular}

médias seguidas de letras minúsculas nas linhas, e iguais, não diferem significativamente entre si $(\mathrm{p}>0.05)$.

c.v. $=21.18 \%$ 
analytical measurements and sensory atributes. Food Chemistry, Kidlingtm, v.60, n.4, p. 659-66, 1997.

HOLLAND, N. Conservação pós-colheita de pêssegos (cv. 'Biuti'): interação entre cálcio e temperatura. 1993. 116p. Dissertação (Mestrado em Ciência dos Alimentos) - Escola Superior de Agronomia de Lavras, Lavras, 1993.
SANDHU, S.S.; DHILLON, B.S.; RANDHAWA, J.S. Chromatographic estimation of sugars from the components of developing fruits of early and late maturing peach cultivars. Journal of Horticultural Science, Ashford, v.58, n.2, p.197-202, 1983.

SCOTT, F.W. HPLC determination of carbohydrates in foods. In: NOLLET, L.M.L. Food analysis by HPLC. New York: Marcel Dekker, 1992.p. 259-74. 